\title{
ANALISIS NERACA AIR LAHAN DI SUB DAS KRUENG JREUE KABUPATEN ACEH BESAR
}

\author{
MAWARDIANA ${ }^{* 1}$, HELMI HASAN BASRI ${ }^{2}$, TARMIZI ${ }^{3}$ \\ ${ }^{* 1}$ Program Studi Agroteknologi Universitas Jabal Ghafur, Sigli \\ ${ }^{2}$ Sekolah Tinggi Ilmu Kehutanan Yayasan Teungku Chik Pante Kulu Banda Aceh \\ ${ }^{3}$ Alumni Sekolah Tinggi Ilmu Kehutanan Yayasan Teungku Chik Pante Kulu Banda Aceh \\ ${ }^{* *}$ Email : ugadeng@yahoo.co.id
}

\begin{abstract}
ABSTRAK
DAS Krueng Aceh (Sub DAS Krueng Jreue) merupakan DAS kritis, termasuk DAS prioritas I seluas 23.218,06 ha. Penelitian dilaksanakan di Daerah Aliran Sungai (DAS) Krueng Aceh, Sub DAS Krueng Jreue Aceh Besar. Penelitian dilaksanakan Desember 2015 sampai dengan Februari 2016. Penelitian menggunakan metode Deskriptif dengan survey lapangan dan analisis di labotarium. Penelitian ini bertujuan untuk menganalisis neraca air lahan di Sub DAS Krueng Jreue. Metode yang digunakan dalam perhitungan neraca air lahan adalah Thornthwaite \& Mather (1957). Hasil analis is menunjukkan bahwa rerata ketersediaan air di Sub DAS Krueng Jreue pada berbagai jenis penggunaan lahan tertinggi dijumpai pada November dan terendah pada Juli. Surplus air hujan terjadi pada Oktober sampai April (7 bulan) dan defisit terjadi pada Mei sampai September ( 5 bulan).Pada berbagai jenis penggunaan lahan, rerata air tanah sangat cukup tersedia dari Oktober hingga Mei (8 bulan), sedangkan kurang tersedia pada Juni hingga September (4 bulan). Persentase air tanah tertinggi terdapat pada hutan primer $(47,20 \%)$, sedangkan yang terendah pada semak belukar $(36,36 \%)$.
\end{abstract}

Kata Kunci: neraca air lahan , DAS Krueng Jreue.

\section{ABSTRACT}

Krueng Aceh River Basin area (Krueng Jreue Sub-watershed) is a critical watershed, including a priority basin I of 23,218.06 ha. The research was conducted in Krueng Aceh River Basin (DAS), Krueng Jreue Sub-district of Aceh Besar. The study was conducted from December 2015 to February 2016. The research used Descriptive method with field survey and analysis in labotarium. This study aims to analyze the water balance of land in Krueng Jreue Subwatershed. The methods used in the calculation of the water balance are Thornthwaite \& Mather (1957). The results showed that the average water availability in Krueng Jreue Subwatersheds on the highest land use varieties was found in November and the lowest in July. The rainfall surplus occurred from October to April ( 7 months) and the deficit occurred from May to September (5 months). In various types of land use, ground water averages are quite available from October to May ( 8 months), while less available in June until September (4 months). The highest percentage of groundwater was found in the primary forest (47.20\%), while the lowest was in the bush $(36.36 \%)$

Keywords: soil waterbalance, Krueng Jreue River Basin area

Diterima: 31 Mei 2018, disetujui : 15 Juli 2018

\section{PENDAHULUAN}

Sub DAS Krueng Jreue dengan DAS Krueng Aceh. Sebagaimana DAS luas 23.218,06 ha salah satu bagian dari yang lainnya, DAS Krueng Aceh tidak 
terlepas dari tekanan yang disebabkan oleh aktivitas manusia di dalamnya. Tingginya pertumbuhan penduduk dan tingkat aktivitas pemanfaatan lahan yang terus meningkat menyebabkan perubahan penggunaan lahan sehingga DAS Krueng Aceh termasuk DAS kritis yang ditetapkan sebagai DAS prioritas berdasarkan Keputusan Menteri Kehutanan Nomor 328 Tahun 2009, dengan prioritas antara lain: tekanan penduduk besar, lahan kritis yang luas dan erosi dan sedimentasi tinggi.

Basri et al., (2013), menyebutkan bahwa selama periode 2006 - 2012 telah terjadi perubahan penggunaan lahan pada Sub DAS Krueng Jreue yang menyebabkan terjadinya pengurangan hutan primer 13.032 .98 ha $(56,53 \%)$ dan hutan lahan kering sekunder 10.299,69 ha $(44,67 \%)$.

Berkurangnya lahan hutan berdampak pada debit air DAS yang semakin berkurang. Ketersediaan air yang ada pada Sub DAS Krueng Jreue berkisar $0,24-3,22 \mathrm{~m} \mathrm{detik}^{-1}$. Sementara total kebutuhan air untuk pertanian dan rumah tangga sebesar 0,18-6,44 $\mathrm{m} \mathrm{detik}^{-1}$ (Isnin et al., 2012). Selain pengurangan lahan berhutan, tingkat kekritisan Sub DAS Krueng Jreue ditandai dengan parameter menurunnya laju infiltrasi tanah, meningkatnya laju erosi, aliran permukaan dan koefisien aliran permukaan.

\section{METODE PENELITIAN}

\section{Lokasi dan waktu Penelitian}

Penelitian dilaksanakan di Daerah Aliran Sungai (DAS) Krueng Aceh, Sub DAS Krueng Jreue. Lokasi penelitian berada pada koordinat $5^{\circ} 22^{\prime}-5^{\circ} 28^{\prime}$ LU dan 95 $32^{\prime}$ - $95^{\circ} 38^{\prime}$ BT dengan luas 23.218,06 ha, berbatasan dengan Sub DAS Krueng Keumireu, Sub DAS Krueng Khee, Sub DAS Krueng Ameuk dan Sub DAS Krueng Aceh Hilir.
Rata-rata laju infiltrasi aktual tertinggi dijumpai pada penggunaan lahan hutan, semak belukar, pertanian lahan kering dan padang rumput, masingmasing sebesar $0,72 \mathrm{~cm} \mathrm{menit}^{-1} ; 0,64$ menit $^{-1} ; 0,64 \mathrm{~cm} \mathrm{menit}{ }^{-1}$ dan $0,58 \mathrm{~cm}$ menit $^{-1}$ (Musna, 2015).

Total erosi dan laju erosi di Sub DAS Krueng Jreue masing-masing adalah 8.029.045,59 ton ha ${ }^{-1} \operatorname{tahun}^{-1}$ dan 345,81 ton ha $^{-1}$ tahun $^{-1}$, katagori berat (BPDAS Krueng Aceh, 2009). Erosi aktual dan erosi potensial terbesar dijumpai pada penggunaan lahan semak belukar yaitu $1.390,21$ ton ha $^{-1}$ tahun $^{-1}$ dan 4.634,05 ton ha $^{-1}$ tahun $^{-1}$ (Siswanda, 2014).Model Soil and Water Assesment Toll (SWAT) memprediksikan dalam kurun waktu 8 tahun (1993 - 2000), Sub DAS Krueng Jreue setiap tahunnya meningkatnya aliran permukaan $2,4 \%$ dan laju erosi $2,3 \%$ pada setiap peningkatan $1 \%$ curah hujan (Ferijal, 2012), dan meningkatnya koefisien aliran permukaan dari 0,12 pada tahun 2006 menjadi 0,24 pada tahun 2012 (Basri et al., 2013). air hujan pada suatu wilayah tertentu, khususnya untuk mengetahui kapan dan seberapa besar surplus dan defisit air yang terjadi di wilayah. Tujuan penelitian adalah untuk mengetahui air masuk dan keluar dari Sub DAS Krueng Jreue dan dengan adanya penelitian ini dampak negatif dan resiko kerusakan banjir dan kekeringan dapat diminimalisir.

Analisis tanah dilaksanakan di Laboratorium Penelitian Tanah dan Laboratorium Fisika Tanah Unsyiah. Penelitian dilaksanakan selama 3 bulan, yaitu Desember 2015 - Februari 2016. Bahan yang digunakan antara lain: peta administrasi, peta jenis tanah, peta kelas kelerengan, peta penggunaan lahan, peta pos pengamatan curah hujan dan peta curah hujan,masing-masing skala 1 : 
50.000 , data curah hujan dan suhu udara periode 2005-2014.

Alat yang digunakan antara lain: deskripsi lapangan,GPS, altimeter, bor tanah,atomic absorption spectrophotometer (AAS), meteran, $\mathrm{pH}$ meter, kamera digital, ring sampel, cangkul, sekop, pisau.

Penelitian

dilakukan menggunakan metode deskriptif dengan survei lapangan dan analisis di Laboratorium. Penelitian ini dibagi atas beberapa tahap, yaitu: (1) tahap persiapan; (2) survei pendahuluan, yaitu melakukan pengecekan lapangan untuk mengetahui keadaan biofisik lahan, khususnya dalam penentuan titik pengamatan pada setiap SPL; (3) survey utama, meliputi pengumpulan data biofisik lahan (morfologi lahan, tanah dan klimatologis); (4) analisis tanah (5) analis is data neraca air lahan.

\section{HASIL DAN PEMBAHASAN}

Analisis NAL dilakukan untuk menganalisis NAL bulanan dan kriteria air tanah tersedia berdasarkan persentase

\section{Analisis Neraca Air Lahan}

Data yang di analisis adalah data curah hujan dan suhu udara bulanan periode 10 tahun 2005-2014 yang berasal dari stasiun Klimatologi Indrapuri. Metode yang digunakan dalam analisis neraca air lahan (NAL) adalah metode Thornthwaite dan Mather (1957). Data masukan yang diperlukan yaitu: curah hujan, evapotranspirasi potensial (ETp), kandungan air tanah pada tingkat kapasitas lapang (KL) dan titik layu permanen (TLP). Persamaan NAL yang digunakan (Pramudia dan Nasrullah, 1991) adalah:

$$
\Delta \mathrm{KAT}=\mathrm{P}-\mathrm{SR}-\mathrm{ET}
$$

dimana :

$\Delta$ KAT $=$ Perubahan kadar air tanah (mm).

$$
\begin{array}{ll}
\mathrm{P} & =\text { Curah hujan }(\mathrm{mm}) \\
\mathrm{SR} & =\text { Aliran permukaan }(\mathrm{mm}) \\
\text { ET } & =\text { Evapotranspirasi }(\mathrm{mm})
\end{array}
$$

Tabel 1. Profil Curah Hujan dan Fluktuasi Suhu Rerata dan ET Sub DAS Krueng Jreue tahun 2005-2014

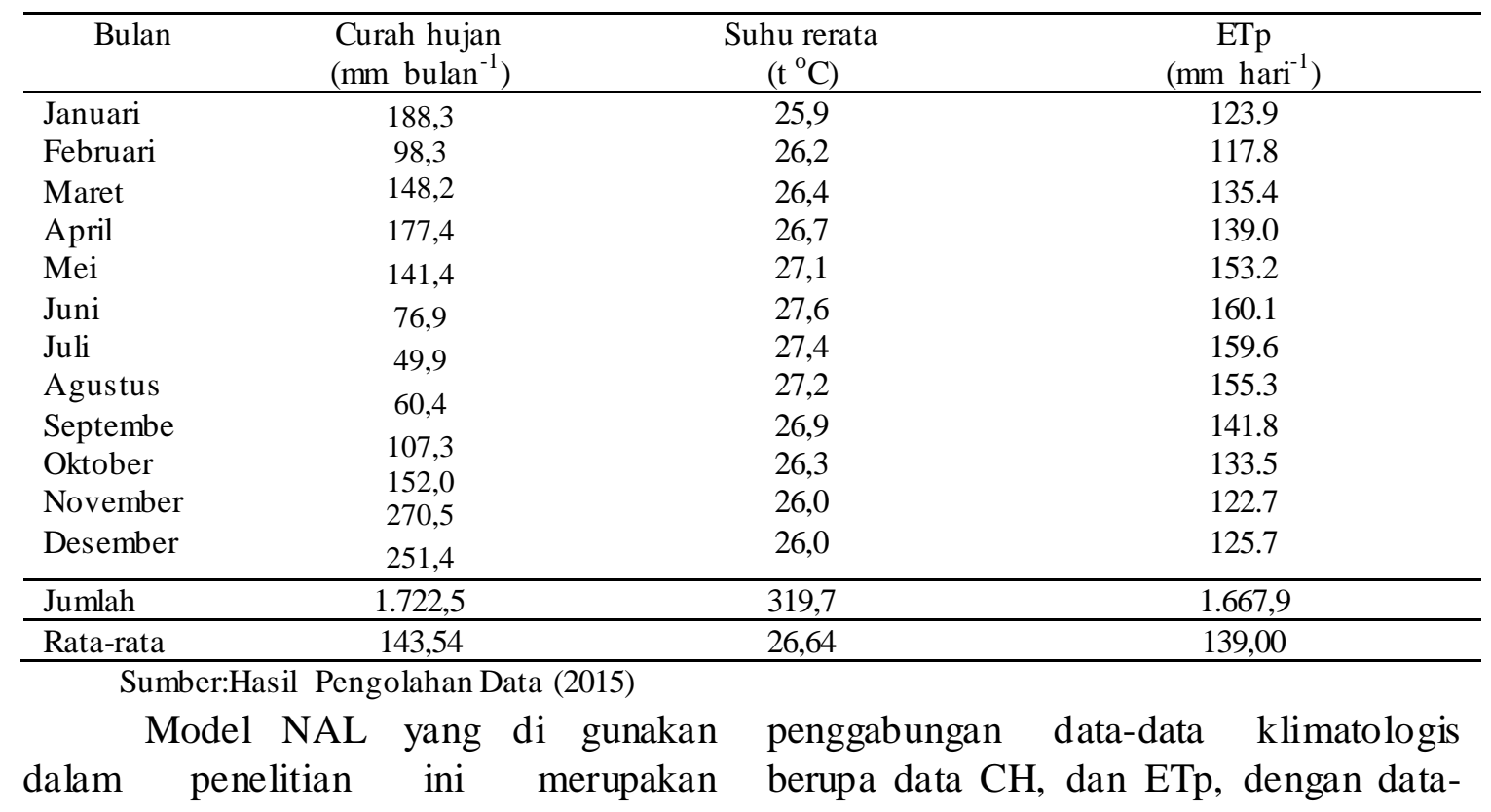


data KL dan KAT yang dihitung dengan mempertimbangkan WHC (Water Holding Capasity) pada TLP, dan APWL (Accumulation Potential of Water Loss). Secara kuantitatif, neraca air menggambarkan prinsip bahwa selama periode waktu tertentu masukan air total sama dengan keluaran air total di tambah dengan perubahan air cadangan (change in storage). Nilai perubahan air cadangan ini dapat bertanda positif atau negatif. Adapun profil ETa, defisit dan surplus air berdasarkan penggunaan lahan, tertera pada Tabel 2.

Tabel 2. Profil ETa, Defisit dan Surplus Air Berdasarkan Penggunaan Lahan Sub DAS Krueng Jreue Tahun 2005-2014

\begin{tabular}{lccc}
\hline $\begin{array}{c}\text { Penggunaan } \\
\text { lahan }\end{array}$ & $\begin{array}{c}\text { ETa } \\
\left(\mathrm{mm} \mathrm{tahun}^{-1}\right)\end{array}$ & $\begin{array}{l}\text { Defisit } \\
\left(\mathrm{mm} \mathrm{tahun}^{-1}\right)\end{array}$ & Surplus $\left(\mathrm{mm} \mathrm{tahun}{ }^{-1}\right)$ \\
\hline Tanah terbuka & $1.428,5$ & 239,4 & 294,0 \\
Semak belukar & $1.428,9$ & 239,0 & 293,6 \\
Padang rumput & $1.425,6$ & 242,3 & 296,9 \\
Pemukiman & $1.433,2$ & 234,7 & 289,3 \\
Sawah & $1.437,6$ & 230,3 & 284,9 \\
Tegalan & $1.428,6$ & 240,0 & 294,6 \\
Hutan sekunder & $1.425,6$ & 237,8 & 292,4 \\
Hutan primer & $1.439,0$ & 228,9 & 283,5 \\
\hline Jumlah & $8.585,2$ & 1892,4 & $2.329,2$ \\
\hline Rerata & 1073,15 & 236,55 & 291,15 \\
\hline
\end{tabular}

Sumber: Hasil pengolahan data (2015)

Tabel 2. menunjukkan, hasil perhitungan NAL ketersediaan air tanah terbuka, terlihat bahwa total hujan selama setahun sebesar $1.722,5 \mathrm{~mm}$, di pergunakan untuk keperluan ETa sebesar $1428,5 \mathrm{~mm}$, sehingga terjadi defisit air sebesar 239,4 mm tahun ${ }^{-1}$ dan surplus 294,0 mm tahun ${ }^{-1}$,sedang pada semak belukar, terlihat bahwa total hujan selama setahun sebesar $1.722,5 \mathrm{~mm}$, di pergunakan untuk keperluan ETa sebesar $1.428,9 \mathrm{~mm}$, terjadi defisit air sebesar 239,0 mm tahun ${ }^{-1}$ dan surplus 293,6 mm tahun $^{-1}$.

Hasil analisis NAL yang mewakili gambaran ketersediaan air padang rumput, terlihat bahwa total hujan selama setahun sebesar 1.722,5 mm, di pergunakan untuk keperluan ETa sebesar 1.425,6 mm sehingga terjadi defisit air sebesar 242,3 mm tahun ${ }^{-1}$ dan surplus sebesar 296,9 mm tahun ${ }^{-1}$,sedangkan pada pemukiman, terlihat bahwa total hujan selama setahun sebesar 1.722,5 mm, dipergunakan untuk keperluan ETa sebesar $1.433,2 \mathrm{~mm}$, terjadi defisit air sebesar 234,7 mm tahun ${ }^{-1}$ dan surplus 289,3 $\mathrm{mm}_{\text {tahun }}{ }^{-1}$.

Hasil perhitungan NAL yang mewakili gambaran ketersediaan air sawah, terlihat bahwa total hujan selama setahun sebesar 1.722,5 mm, dipergunakan untuk keperluan ETa sebesar 1.437,6 mm, sehingga terjadi defisit air sebesar 230,3 mm tahun ${ }^{-1}$ dan surplus $284,9 \mathrm{~mm}$ tahun $^{-1}$, sedangkan pada tegalan, terlihat bahwa total hujan selama setahun sebesar 1.722,5 mm, dipergunakan untuk keperluan ETa sebesar 1.428,6 mm, terjadi defisit air sebesar 240,0 mm tahun $^{-1}$ dan surplus 294,6 mm tahun ${ }^{-1}$.

Hasil perhitungan NAL yang mewakili gambaran ketersediaan air hutan sekunder terlihat bahwa total hujan selama setahun sebesar $1.722,5 \mathrm{~mm}$, dipergunakan untuk keperluan ETa sebesar 1.425,6 $\mathrm{mm}$, sehingga terjadi defisit air sebesar $237,8 \mathrm{~mm}_{\text {tahun }}{ }^{-1}$ dan surplus $292,4 \mathrm{~mm}$ tahun $^{-1}$,sedangkan pada 
hutan primer terlihat bahwa total hujan selama setahun sebesar $1.722,5 \mathrm{~mm}$, di pergunakan untuk keperluan ETa sebesar $1.439,0 \mathrm{~mm}$, terjadi defisit air sebesar $228,9 \mathrm{~mm}$ tahun $^{-1}$ dan surplus $283,5 \mathrm{~mm}$ tahun $^{-1}$.

Terdapat hubungan nilai antara $\mathrm{CH}$ dengan ETp. Hasil analisis memberikan gambaran ketersediaan air pada masing-masing penggunaan lahan sehingga dapat diketahui ketersediaan air. Apabila curah hujan melebihi ET maka akan terjadi surplus air pada lahan dan sebaliknya jika curah hujan lebih kecil dari ET maka akan terjadi defisit pada lahan. Menurut Jackson (1977), neraca air merupakan perimbangan yang terjadi antara $\mathrm{CH}$ dan laju ETp. Apabila curah hujan melebihi ETp (P>ETp), maka terjadi peningkatan air tanah sehingga air cukup tersedia bahkan lahan mengalami kelebihan air atau surplus (S), dan sebaliknya jika curah hujan lebih kecil dari ETp (P < ETP), akan berkurang kandungan air dalam tanah bahkan dapat mencapai keadaan defisit (D).

Menurut Nasir (2002) periode surplus atau defisit air suatu lahan penting di ketahui untuk mengatur pola tanam maupun jadwal pemberian air irigasi, sehingga dengan pengelolaan berdasarkan acuan hasil perhitungan neraca air di harapkan akan di peroleh produksi pertanian yang lebih baik. Dalam rangka menstabilkan produksi tanaman, sangat memungki kan untuk dikembangkan sumber-sumber air baru, seperti

\section{KESIMPULAN}

Rerata ketersediaan air di Sub DAS Krueng Jreue pada berbagai penggunaan lahan tertinggi dijumpai pada bulan November dan terendah pada bulan Juli. Surplus air hujan terjadi pada bulan Oktober-April (7 bulan) dan defisit terjadi pada bulan Mei-September (5 bulan). Pada berbagai penggunaan lahan, rerata kelembaban tanah maupun air tanah pada suatu lahan (Moroizumi et al., 2009).

\section{Interpretasi Neraca Air Lahan}

Hasil perhitungan NAL di dapatkan kurva yang memberi gambaran mengenai saat-saat lahan mengalami kelebihan air dan kekurangan air. Berdasarkan kurva NAL memperlihatkan bahwa nilai ETp melebihi curah hujan pada bulan Mei sampai September, kecuali pada bulan pada bulan Oktober sampai April mengalami surplus curah hujan, dengan demikian pada bulan-bulan tersebut di jadikan dasar awal dari masa tanam.

Ketersediaan air tanah pada musim kering akan mengalami penurunan. Nilai simpanan air (kelembaban) berada diantara nol dan kapasitas maksimum tanah menyimpan air (water holding capacity), Nilai WHC ditentukan oleh porositas tanah dan kedalaman akar. Hasil analisis, porositas total pada setiap SPL berkisar39,45,2\% (kurang baik) sampai 52,41\% (baik). Daya kemampuan tanah menyimpan air tergantung dari porositas tanah. Hasil penelitian diketahui bahwa perbedaan kond isi permukaan tanah, tekstur, struktur dan vegetasi merupakan faktor penyebab terjadinya perbedaan kapasitas menyimpan air. Pergerakan air maupun laju perubahan kadar air dalam tanah sangat ditentukan oleh karakteristik pori tanah yang menyusun struktur tanah, seperti distribusi pori, kontinuitas pori, dan tortuositas pori (Hillel, 1998).

air tanah sangat cukup tersedia dari bulan Oktober-Mei ( 8 bulan), sedangkan kurang tersedia pada bulan Juni-September (4 bulan). Persentase air tanah tertinggi terdapat pada hutan primer $(47,20 \%)$, sedangkan yang terendah pada semak belukar $(36,36 \%)$. 


\section{DAFTAR PUSTAKA}

Basri, H., Helmi, Pratiwi, H. 2013. Pengaruh perubahan penggunaan lahan terhadap koefisien limpasan dan debit puncak di Sub DAS Krueng Jreue. Jurnal Sains Riset, Vol. 3, No. 2, hlm. 16-23. ISSN 2088- 0952. Universitas Jabal Ghafur (UNIGHA). Sigli.

BPDAS Krueng Aceh. 2009. Laporan Utama Identifikasi Karakteristik DAS krueng Aceh. Badan Pengelolaan Daerah Aliran Sungai Krueng Aceh. Departemen Kehutanan. Banda Aceh.

Ferijal, T. 2012. Prediksi hasil limpasan permukaan dan laju erosi dari Sub DAS Krueng Jreue menggunakan model SWAT. Jurnal Agrista Vol. 16, No. 1, 2012. ISSN: 1410-3389. Fakultas Pertanian, Universitas Syiah Kuala (UNSYIAH). Banda Aceh.

Hilel, D. 1998.Pengantar Fisika Tanah. Edisi Pertama. Terjemahan Robianto, H. S. dan Rahmad, H. P. Mitra Gama Widya. Yogyakarta.

Isnin, M., Basri, H., Ramano. 2012. Nilai ekonomi ketersediaan hasil air dari Sub DAS Krueng Jreue Kabupaten Aceh Besar. Jurnal Manajemen Sumberdaya Lahan, Vol. 1, No. 2, Desember 2012, hlm. 184-193. Fakultas Pertanian, Universitas Syiah Kuala (UNSYIAH). Banda Aceh.
Musna, H. 2015. Analisis Laju Infiltrasi pada Berbagai Tipe Penggunaan Lahan di Sub DAS Krueng Jreue. Skripsi. Program Studi Agroteknologi, Fakultas Pertanian. Universitas Syiah Kuala (UNSYIAH). Darussalam-Banda Aceh.

Moraizumi, T., Hamada, H., Sukchan, S., Ikemoto, M. 2009. Soil water content and balance in rainfed fields in Northeast Thailand. Agricultural Water Management. Volume 96, Issue 1, January 2009, Pages 160166.

Nasir, A. 2002.Neraca Air Agroklimatik.Makalah Pelatihan Bimbingan Pengamanan Tanaman Pangan dan Bencana Alam. Bogor.

Siswanda. 2014. Prediksi Erosi Sub DAS Krueng Jreue Kabupaten Aceh Besar. Skripsi. Program Studi Agroteknologi, Fakultas Pertanian. Universitas Syiah Kuala (UNSYIAH). Darussalam-Banda Aceh.

Thornthwaite, C.W., Mather, J.R. 1957. Instructions and tables for Computing potential evapotranspiration and the water balance. Publication. in Climatology. Vol.X No.3. Drexel Inture of Tecnology Laboratory of Climatology, Centerton, New Jersey. pp.185-311. 